\title{
IMPLEMENTASI PROGRAM LAYANAN SEHARI SELESAI (LARI SAY) PADA DINAS KEPENDUDUKAN DAN PENCATATAN SIPIL KOTA BANJARBARU
}

\author{
Sitna Hajar Malawat, Evy Emy Liantie \\ FISIP, Universitas Islam Kalimantan Muhammad Arsyad Al Banjari \\ Email : $\underline{\text { Sitna.shm@gmail.com eviemyliantie07@ gmail.com }}$
}

\begin{abstract}
The purpose of the study was to find out the description of how the implementation and the factors that influence the Completion of a Day Service Program (LARI SAY) at the Banjarbaru City Population and Civil Registration Service. The research method used a qualitative approach with descriptive type. Collection by interview and observation, to 5 (five) informants. Informants were determined using descriptive techniques. Data analysis using interactive models according to Miles \& Huberman.

The results of the study showed the Implementation of a One-Day Service Program (LARI SAY) at the Banjarbaru City Population and Civil Registration Service, viewed from Communication Indicators, Resource Indicators, Bureaucratic Structural Indicators, which were considered not optimal because they were still being repaired and improved while the Disposition Indicator was running optimally because in matters of disposition signing a service document a day is finished always done according to the procedure and time. The factors that affect consist of 2 (two) namely supporting factors and inhibiting factors. Supporting factors are a. Human Resources (HR); b. Disposition; and c. facilities and infrastructure while the inhibiting factor is a. network system; $b$. communication; and c. human behavior.
\end{abstract}

Keywords: Implementation, Services, Say Sprint Program

\section{LATAR BELAKANG MASALAH}

Implementasi Undang-Undang Nomor 25 Tahun 2009 pasal 7 ayat (4) huruf c, tentang pelayanan publik. Penyelenggaraan pelayanan publik merupakan upaya negara untuk memenuhi kebutuhan dasar dan hak-hak sipil setiap warga negara atas barang, jasa, dan pelayanan administratif yang disediakan oleh pemerintah. Undang-Undang Dasar 1945 mengamankan kepada negara untuk memenuhi kebutuhan dasar setiap warga negara demi kesejahteraannya, sehingga efektivitas suatu sistem pemerintahan sangat ditentukan oleh baik buruknya penyelenggaraan pelayanan publik. $\begin{array}{ccc}\text { Dalam Undang-Undang } & \text { Nomor } 24 \\ \text { Tahun } & 2013 \quad \text { tentang Administrasi }\end{array}$ Kependudukan, perbaikan pelayanan yang membuat Dinas Kependudukan dan Pencatatan Sipil Kota Banjarbaru sedikit demi sedikit membenahi layanan administrasi kependudukan. Menurut Damanpour (dalam Suwarno 2008) mengatakan bahwa "Pelayanan inovasi dapat berupa produk atau jasa yang baru, teknologi yang baru, sistem struktur dan administrasi baru atau rencana baru bagi anggota organisasi.

Dengan permasalahan waktu dan kemudahan dalam birokrasi maka Dinas Kependudukan dan Pencatatan Sipil Kota 
Banjarbaru membuat upaya inovasi yaitu Layanan Sehari Selesai atau dikenal dengan LARI SAY yang telah ditetapkan oleh Walikota Banjarbaru sebagai slogan berdasarkan SK Walikota Banjarbaru Nomor 188.45/328/KUM/2017. Layanan LARI SAY digunakan untuk mengurus administrasi kependudukan.

Permasalahan muncul karena ketidaktahuan dan tidak lengkap membawa persyaratan sehingga program ini tidak terlaksana dengan semestinya. Yang seharusnya sehari menjadi berhari-hari dengan alasannya dokumen tidak dapat diproses karena ketidaklengkapan persyaratan. Sehingga program LARI SAY tidak dapat berjalan dengan baik jika pada implementasinya tidak sesuai prosedur. Untuk dapat terus mengupayakan pelayanan publik yang berkualitas diperlukan adanya suatu analisis terhadap implementasi program inovasi LARI SAY ini. Dimana, analisis ini nantinya akan mengungkapkan akar dari permasalahan yang terjadi, sehingga kualitas pelayanannya dapat ditingkatkan lagi di masa mendatang. Berdasarkan permasalahan tersebut maka peneliti merasa tertarik untuk menganalis implementasi program Layanan Sehari Selesai dengan melakukan penelitian yang berjudul "Implementasi Program Layanan Sehari Selesai (LARI SAY) Pada Dinas Kependudukan dan Pencatatan Sipil Kota Banjarbaru".

\section{Rumusan Masalah}

1. Bagaimanakah Implementasi Program Layanan Sehari Selesai (LARI SAY) Pada Dinas Kependudukan dan Pencatatan Sipil Kota Banjarbaru ?

2. Apa sajakah faktor yang berpengaruh pada Implementasi Program Layanan Sehari Selesai (LARI SAY) Pada Dinas Kependudukan dan Pencatatan Sipil Kota Banjarbaru.

\section{Tujuan Penelitian}

1. Untuk mengetahui Bagaimanakah Implementasi Program Layanan Sehari Selesai (LARI SAY) Pada Dinas Kependudukan dan Pencatatan Sipil Kota Banjarbaru.
2. Untuk mengetahui Apa sajakah faktor yang berpengaruh pada Implementasi Program Layanan Sehari Selesai (LARI SAY) Pada Dinas Kependudukan dan Pencatatan Sipil Kota Banjarbaru.

\section{Kegunaan Penelitian}

\section{Kegunaan Teoritis}

Penelitian diharapkan dapatmenambah hasanah bacaan dan dapat digunakan sebagai refrensi atau bahan pustaka bagi para peneliti berikutnya .

\section{Kegunaan Praktis}

Sebagai bahan refleksi bagi instansi diharapkan hasil penelitian ini dapat menjadi masukan berupa informasi untuk mengetahui bagaimana Implementasi Program LARI SAY pada Disdukcapil Kota Banjarbaru sudah baik atau perlu ditingkatkan lagi.

\section{TINJAUAN PUSTAKA}

\section{Konsep Implementasi}

Implementasi atau pelaksanaan merupakan kegiatan yang penting dari keseluruhan proses perencanaan program/kebijakan. Kebijakan yang telah direkomendasikan untuk dipilih oleh policy makers bukanlah jaminan bahwa kebijakan tersebut pasti berhasil dalam implementasinya. Ada banyak variabel yang mempengaruhi keberhasilan implementasi kebijakan baik bersifat individual maupun kelompok atau institusi. Implementasi dari suatu program melibatkan upaya-upaya policy makers untuk mempengaruhi perilaku birokrat pelaksana agar bersedia memberikan pelayanan dan mengatur perilaku kelompok sasaran. (Subarsono, 2013) .

Dari uraian diatas dapat diketahui bahwa implementasi kebijakan terdiri dari tujuan atau sasaran kebijakan, pelaksanan kebijakan dan pencapaian tujuan dari hasil kegiatan. Sehiingga peneliti berkesimpulan implementasi merupakan sebuah aktivitas tindakan yang sesuai dengan tujuan dan sasarannya. 


\section{Konsep Pelayanan Publik}

Thoha (dalam Anggara, 2012), menjelaskan bahwa pelayanan masyarakat merupakan suatu usaha yang dilakukan oleh seseorang atau sekelompok orang atau institusi tertentu untuk memberikan bantuan kemudahan kepada masyarakat dalam rangka mencapai tujuan tertentu. Birokrasi pemerintah merupakan institusi terdepan yang berhubungan dengan pemberian pelayanan masyarakat.

Pengertian pelayanan umum berdasarkan Pedoman Tata Laksana Pelayanan Umum (KEMENPAN 81/1993, 1993 3) adalah segala bentuk kegiatan pelayanan umum yang dilaksanakan oleh instansi pemerintah di pusat, di daerah, di lingkungan badan usaha milik negara atau daerah dalam bentuk barang dan jasa, baik dalam rangka pemenuhan kebutuhan masyarakat maupun dalam rangka pelaksanaan ketentuan peraturan perundang-undangan.

Dari uraian dan pendapat para ahli di atas, dapat peneliti simpulkan bahwa pelayanan publik adalah serangkaian kegiatan yang dilakukan pemerintah sesuai dengan peraturan perundangundangan yang ada guna memenuhi kebutuhan masyarakat dan bertujuan untuk meningkatkan kesejahteraan.

\section{Konsep Layanan Sehari Selesai (LARI} SAY)

Layanan Sehari Selesai atau dikenal dengan LARI SAY adalah program yang dilakukan Dinas Kependudukan dan Pencatatan Sipil Banjarbaru untuk menyingkat waktu pelayanan serta memberikan kenyamanan dalam mengurus dokumen kependudukan.

\section{METODE PENELITIAN}

$\begin{array}{ll}\text { Metode } & \text { penelitian menggunakan } \\ \text { pendekatan } & \text { kualitatif dengan tipe } \\ \text { deskriptif. } & \text { Pengumpulan dengan }\end{array}$ wawancara dan observasi, kepada 5 (lima) orang informan. Informan ditentukan dengan menggunakan teknik deskriptif. Analisis data menggunakan model interaktif menurut Miles \& Huberman.

Penelitian ini bertempat di Dinas Kependudukan dan Pencatatan Sipil Kota Banjarbaru terletak di Jalan Jendral Sudirman No. 3 Loktabat Utara, Banjarbaru Utara, Kota Banjarbaru, Kalimantan Selatan 70711. Waktu Penelitian dilaksanakan selama 4 (empat) bulan, yaitu dimulai pada Oktober 2018 sampai dengan Januari 2019.

\section{HASIL DAN PEMBAHASAN}

Dinas Kependudukan dan Pencatatan Sipil Kota Banjarbaru ini terletak di Jl. Jendral Sudirman No. 3 Kelurahan Loktabat Utara Kecamatan Banjarbaru Utara Kota Banjarbaru, Kalimantan Selatan 70711.

Visi yaitu : "Terwujudnya Pelayanan Administrasi Kependudukan Dan Pencatatan Sipil Yang Berkarakter". 
Misi yaitu :

1. Meningkatkan Kualitas Pelayanan Kependudukan Dan Pencatatan Sipil 2. Meningkatkan Tertib Administrasi Kependudukan Dan Pencatatan Sipil 3. Meningkatkan Akurasi Database Kependudukan

4. Meningkatkan Pelayanan Dan Akuntabilitas Kinerja.

\section{Hasil Penelitian}

\section{Implementasi program Layanan Sehari Selesai (LARI SAY) Pada Dinas Kependudukan dan Pencatatan Sipil Kota Banjarbaru}

\section{Indikator Berdasarkan Komunikasi}

Berdasarkan hasil penelitian indikator komunikasi bahwa dalam implementasi program layanan sehari selesai (LARI SAY) pada Dinas Kependudukan dan Pencatatan Sipil Kota Banjarbaru tentang komunikasi berupa sosialisasi belum berjalan optimal dikarenakan sosialisasi hanya dilakukan melalui website dan penyuluhan kelurahan dimana masyarakat masih banyak yang belummengetahui program ini . Informasi persyaratan yang kurang efektif menjadi kendala masyarakat dalam layanan ini karena yang seharusnya sehari menjadi berharihari terhambat oleh ketidaklengkapan syarat dokumen.

\section{Indikator Berdasarkan Sumber Daya}

Berdasarkan hasil penelitian indikator sumber bahwa dalam implementasi program layanan sehari selesai (LARI SAY) pada Dinas Kependudukan dan Pencatatan Sipil Kota Banjarbaru tentang sumber daya berupa kecepatan pelayanan belum berjalan optimal dikarenakan masyarakat masih banyak tidak mengetahui dalam kelengkapan syarat dokumen sehingga masyarakat bolak-balik mengurus syarat yang belum ada, ini berpengaruh pada kecepatan pelayanan yang mana masyarakat merasa terbuang waktunya hanya utuk mengurus dokumen kependudukan berhari-hari. Namun terdukung dengan penyediaan sarana prasarana yang memadai seperti ruang pelayanan yang nyaman, adanya ruang bermain anak, ruang khusus ibu menyusui serta fasilitas bagi penyandang disabilitas.

\section{Indikator Berdasarkan Disposisi}

Berdasarkan hasil penelitian indikator bahwa dalam implementasi program layanan sehari selesai (LARI SAY) pada Dinas Kependudukan dan Pencatatan Sipil Kota Banjarbaru tentang disposisi pegawai sudah berjalan dengan optimal karena dalam urusan disposisi penandatanganan dokumen layanan sehari selesai selalu di kerjakan dengan semestinya walaupun berhalangan tetapi selalu disempatkan sehingga tidak ada hambatan dalam hal tanda tangan dokumen yang diperlukan masyarakat yang sesuai dengan program yaitu sehari selesai dalam catatan semua dokumen lengkap sehingga dalam proses input pembuatan sampai penadatanganan berjalan lancar sesuai prosedur, dan didukung oleh sikap pegawai dalam memberikan pelayanan kepada masyarakat dengan ramah dan murah senyum sehingga menjadi nilai plus bagi pegawai karena dinilai masyarakat baik.

\section{Indikator Berdasarkan Struktur Birokrasi}

Berdasarkan hasil bahwa dalam implementasi program layanan sehari selesai (LARI SAY) pada Dinas Kependudukan dan Pencatatan Sipil Kota Banjarbaru tentang struktur birokrasi berupa Standar Operatioanl Procedures SOPs belum berjalan optimal dikarenakan masyarakat banyak yang belum mengetahui alur pelayanan LARI SAY serta persyaratan untuk mengurus program LARI SAY ini. Dimana inovasi ini bertujuan untuk meningkatkan kenyamanan pengguna layanan, meningkatkan partisipasi serta kearifan masyarakat, kemudahan akses informasi mengenai jenis dan persyaratan pelayanan publik, meningkatkan efisiensi dan efektivitas waktu pelayanan dan mengurangi kerumitan birokrasi dan mengurangi bahkan menghilangkan pungutan liar ataupun sistem percaloan dalam pengurusan dokumen kependudukan. Tetapi pada nyatanya masyarakat masih mengeluhkan informasi persyaratan yang tidak detail sehingga masyarakat masih banyak yang bolak-balik karena syarat yang belum terpenuhi sesuai prosedur.

Sehingga Dilihat dari 4 (empat) indikator pada teori implementasi kebijakan publik tersebut hanya indikator disposisi 
yang menunjukkan hasil yang cukup baik sedangkan indikator lainnya seperti komunikasi, sumber daya, dan struktur birokrasi masih perlu di lakukan peningkatan.

\section{Faktor Yang Berpengaruh Pada Implementasi Program Layanan Sehari Selesai (LARI SAY) Pada Dinas Kependudukan dan Pencatatan Sipil Kota Banjarbaru}

Implementasi program Layanan Sehari Selesai mempunyai dua faktor yang berpengaruh yang terdiri dari :

\section{Faktor Pendukung}

Berdasarkan hasil penelitian faktor yang berpengaruh dalam implementasi program layanan sehari selesai (LARI SAY) pada Dinas Kependudukan dan Pencatatan Sipil Kota Banjarbaru yaitu Sumber Daya Manusia, Disposisi, Sarana dan Prasarana yang sudah berjalan optimal karena ketiga faktor ini sangat membantu dalam implementasi program lari say di DISDUKCAPIL Banjarbaru dalam meningkatkan kualitas dan kenyamanan yang rasakan oleh masayarakat dan dijalankan oleh pegawai.

\section{Faktor Penghambat}

Berdasarkan hasil penelitian faktor penghambat dalam implementasi program layanan sehari selesai (LARI SAY) pada Dinas Kependudukan dan Pencatatan Sipil Kota Banjarbaru yaitu terjadinya gangguan pada sistem jaringan dalam proses input data, komunikasi berupa sosialisasi yang masih kurang karena masyarakat masih banyak yang tidak mengetahui program lari say ini dan perilaku manusia dalam pengetahuan untuk tidak mencari tahu tentang program ini karena pada dasarnya pihak DISDUKCAPIL sudah mensosialisasikan program ini dikelurahan dan website resmi DISDUKCAPIL. Program ini akan berjalan dengan optimal jika dukungan masyarakat ikut partisipasi dalam pengimplementasian program ini.
Namun masyarakat masih banyak yang acuh dalam mengali informasi tentangprogram lari say ini karena ketidakpedulian, padahal DISDUKCAPIL sudah membuat SOPs program ini dengan baik.

\section{Kesimpulan}

1. Implementasi program Layanan Sehari Selesai (LARI SAY) Pada Dinas Kependudukan dan Pencatatan Sipil Kota Banjarbaru, dilihat dari : 1. Indikator Komunikasi, belum berjalan optimal dikarenakan sosialisasi hanya dilakukan melalui website dan penyuluhan kelurahan, sehingga masyarakat masih banyak yang belum mengetahui program ini; 2. Indikator Sumber Daya, belum berjalan optimal dikarenakan kecepatan pelayanan yang berpengaruh pada ketidaktahuan masyarakat dalam persyaratan dokumen kependudukan; 3. Indikator Disposisi, sudah berjalan dengan optimal karena dalam urusan disposisi penandatanganan dokumen layanan sehari selesai selalu di kerjakan sesuai prosedur dan waktunya; dan 4. Indikator Struktrur birokrasi, Standar Operatioanl Procedures (SOPs) belum berjalan optimal dikarenakan masyarakat banyak yang belum mengetahui alur pelayanan LARI SAY serta persyaratan untuk mengurus program LARI SAY ini . Sehingga perlu adanya perbaikan dan peningkatannya lagi untuk kedepannya bagi Dinas Kependudukan dan Pencatatan Sipil Kota Banjarbaru.

2. Adapun faktor yang mempengaruhi terdiri dari 2 (dua) yaitu faktor 
pendukung dan faktor penghambat. Faktor pendukung adalah a. Sumber Daya Manusia (SDM) ; b. Disposisi; dan c. Sarana Dan Prasarana sedangkan faktor penghambat adalah a. Sistem Jaringan; b. Komunikasi; dan c. Perilaku Manusia.

\section{Saran}

1. Implementasi program Layanan Sehari Selesai (LARI SAY) Pada Dinas Kependudukan dan Pencatatan Sipil Kota Banjarbaru program ini perlu disosialisasikan kepada masyarakat secara continue baik secara langsung maupun berupa tulisan banner atau spanduk yang menarik.

2. Masyarakat seharusnya lebih aktif ikut dalam berpartisipasi meimplementasikan program yang ada di DISDUKCAPIL ini seperti mengetahui dan mencari tahu tentang program apa saja yang diberikan dan masyarakat menjadi up-to-date dalam hal pelayanan sehingga kebijakan yang dibuat oleh pemerintah didukung oleh masyarakat agar berjalan dengan baik.

\section{DAFTAR PUSTAKA}

\section{Literatur}

Abidin, Said Zainal. 2012. Kebijakan Publik. Jakarta: Salemba Humanika.

Anggara, Sahya. 2012. Ilmu Administrasi Negara. Bandung: CV Pustaka Setia.

Mahmudi. 2010. Manajemen Kinerja Sektor Publik. Yogyakarta: UPP STIM YKPN.

Moleong, Lexy J. 2007. Metodologi Penelitian Kualitatif. Bandung: PT Remaja Rosdakarya Offset.

Sinambela, Lijan Poltak. 2008. Reformasi Pelayanan Publik. Jakarta.: Aksara Bumi.
Subarsono. 2013. Analisis Kebijakan Publik. Yogyakarta: Pustaka Pelajar. Sugiyono. 2005. Metode Penelitian Administrasi. Bandung: Alfabeta.

Sugiyono. 2009. Metode Penelitian Kuantitatif Dan Kualitatif. Bandung: Alfabeta.

Sugiyono. 2015. Metode Penelitian Dan Pengembangan Research And Development. Bandung: Alfabeta.

Sunggono, Bambang. 1994. Hukum Dan Kebijaksannan Publik. Jakarta: PT Karya Unipress.

Suwarno,Yogi.2008. Inovasi Disektor Publik. Jakarta: STIA-LAN.

Uniska, TF. 2018. Panduan Penulisan Skripsi. Banjarmasin: FISIP UNISKA.

Wahab, Solichin Abdul. 2015. Analisis Kebijakan Publik Dari Formulasi Ke Penyusunan Model-Model Implementasi Kebijakan Publik. Jakarta: PT Bumi Aksara.

\section{Peraturan Perundang-Undangan}

Undang-Undang Nomor 25 Tahun 2009 Tentang Pelayanan Publik.

Undang-Undang Nomor 30 Tahun 2014 Tentang Administrasi Pemerintahan.

Undang-Undang Nomor 24 Tahun 2013 Tentang Administrasi Kependudukan.

Keputusan Mentri Pendayagunaan Aparatur Negara Nomor 81 Tahun 1993 Tentang Pedoman Tata Laksana Pelayanan Umum.

SK Walikota Banjarbaru Nomor 188.45/328/KUM/2017 Tentang Layanan Sehari Selesai.

\section{Jurnal}

Hayati. 2017. Implementasi Penerapan Asas Pelayanan Yang Baik Dalam Meningkatkan Kinerja. Jurnal Hukum Admnistrasi Negara. 4(1):191. 
Hisbani, dkk. 2015. Penerapan Inovasi Pelayanan Publik di Dinas Kependudukan dan Catatan Sipil Kabupaten Enrekang.Junal Administrasi

Publik.1(3):266.

Widhiastiti, dkk. 2017. Implementasi Program Pencatatan Akta Kelahiran Berbasis Online (Studi Kasus Program Inovasi Capil Online Pada Dinas Kependudukan Dan Pencatatatn Sipil Kota Denpasar). Jurnal Ilmu Sosial Dan Ilmu Politik. 1(1):3. 
